\title{
Refinement of the crystal structure of scandium diiron disilicide, $\mathrm{ScFe}_{2} \mathrm{Si}_{2}$
}

\author{
B. Y. Kotur*, R. Cerny, J. V. Pacheco and K. Yvon \\ Université de Genève, Laboratoire de Cristallographie, 24, quai Emest-Ansermet, CH-1211 Geneva 4, Switzerland
}

Received July 1, 1996, transferred to 2nd update of database ICSD in 1997, CSD-No. 402545

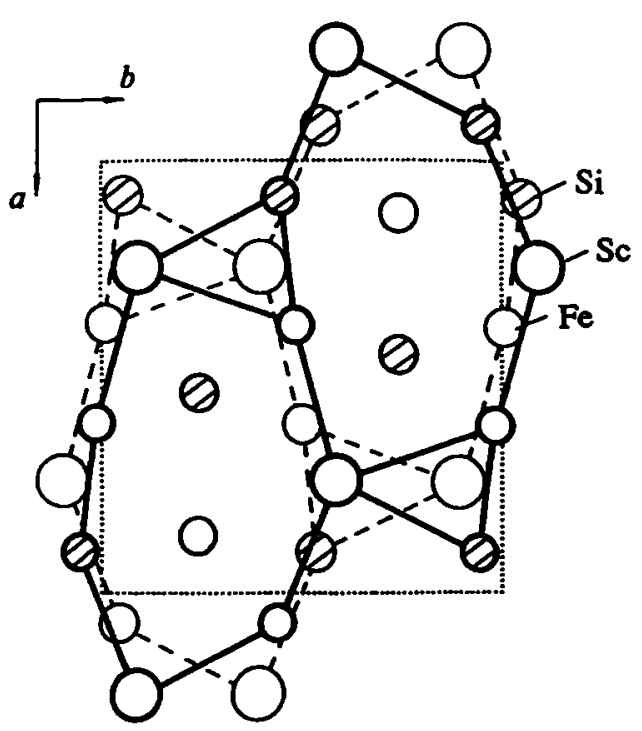

Source of material: Pieces of scandium, iron and silicon were arc melted in argon atmosphere. A single crystal of prismatic shape was extracted from the alloy which was homogenated in an evacuated quartz tube at $1073 \mathrm{~K}$ during 15 days.

$\mathrm{Fe}_{2} \mathrm{ScSi}$, orthorhombic, $\mathrm{Pbcm}$ (No. 57), $a=7.5002(9) \AA$, $b=7.1375(9) \AA, c=5.0224(4) \AA, V=268.9 \AA^{3}, Z=4, R(F)=0.040$, $R_{\mathrm{W}}(F)=0.023$.

Table 2. Final atomic coordinates and displacement parameters (in $\AA^{2}$ )

\begin{tabular}{|c|c|c|c|c|c|c|c|c|c|c|}
\hline Atom & Site & $x$ & $y$ & $z$ & $U_{11}$ & $U_{22}$ & $U_{33}$ & $U_{12}$ & $U_{13}$ & $U_{23}$ \\
\hline $\mathrm{Sc}$ & $4 d$ & $0.2511(3)$ & $0.4028(3)$ & $1 / 4$ & $0.0027(7)$ & $0.0047(7)$ & $0.0047(8)$ & $0.0008(6)$ & 0 & 0 \\
\hline $\mathrm{Fe}(1)$ & $4 d$ & $0.3843(2)$ & $0.0115(2)$ & $1 / 4$ & $0.0036(6)$ & $0.0033(6)$ & $0.0041(7)$ & $-0.0008(6)$ & 0 & 0 \\
\hline $\mathrm{Fe}(2)$ & $4 c$ & $0.8824(2)$ & $1 / 4$ & 0 & $0.0043(6)$ & $0.0042(5)$ & $0.0042(6)$ & 0 & 0 & $0.0005(5)$ \\
\hline $\operatorname{Si}(1)$ & $4 d$ & $0.0832(3)$ & $0.0500(4)$ & $1 / 4$ & $0.005(1)$ & $0.006(1)$ & $0.006(1)$ & $-0.001(1)$ & 0 & 0 \\
\hline $\operatorname{Si}(2)$ & $4 c$ & $0.5479(3)$ & $1 / 4$ & 0 & $0.003(1)$ & $0.006(1)$ & $0.006(1)$ & 0 & 0 & $-0.001(1)$ \\
\hline
\end{tabular}

\section{References}

1. Blanc, E.; Schwarzenbach, D.; Flack, H. D.: The Evaluation of Transmission Factors and their First Derivatives with Respect to Crystal Shape Parameters. J. Appl. Crystallogr. 24 (1991) 1035-1041.

2. Gelato, L. M.; Parthe, E.: STRUCTURE TIDY - a computer program to standardize crystal structure data. J. Appl. Crystallogr. 20 (1987) 139-143.
The synthesis and $\mathrm{X}$-ray structure of $\mathrm{ScFe}_{2} \mathrm{Si}_{2}$ was reported before (see ref. 3). The compound was found to crystallize with the $\mathrm{HfFe}_{2} \mathrm{Si}_{2}$ structure type (see ref. 5). Both structures were established on single crystals from photographic data. Here we report the first single crystal counter data on that structure type. As shown in the figure, the structure of $\mathrm{ScFe}_{2} \mathrm{Si}_{2}$ can be described in terms of nets which connect Sc, Fel and Sil atoms at $z=1 / 4$ (dashed lines), and at $z=3 / 4$ (full lines), and of additional $\mathrm{Fe} 2$ and $\mathrm{Si} 2$ atoms which are both situated at the heights $z=0$ and $z=0.5$. Scandium is the only rare earth element which participates in the formation of that structure type for which the two above compounds are the only known members to date.

Table 1. Parameters used for the X-ray data collection

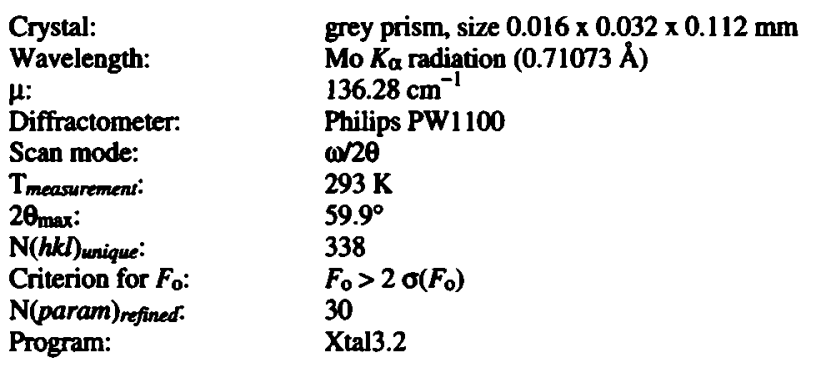
scandium-iron-silicon system. Dopovidi Akad. Nauk Ukrain. RSR, Ser. A. No 8 (1977) 751-754.

4. Hall, S. R.; Flack, H. D.; Stewart J. M.: Eds. Xtal3.2. Reference Manual. Universities of Western Australia, Geneva and Maryland 1992.

5. Yarmolyuk, Ya. P.; Lysenko, L. A.; Gladyshevskii, E. I.: Crystal structure of the compound HfFes $\mathrm{Si}_{2}$. Sov. Phys. Crystallogr. 21 (1976) 473-475. 